\title{
In silico Docking Analysis of Active Biomolecules from Cissus quadrangularis L. against PPAR- $\gamma$
}

\author{
Vishal Shivalingappa Patil, Prakash Rajashekhar Biradar, Vasim Attar, Pukar Khanal* \\ Department of Pharmacology, KLE College of Pharmacy, KAHER, Belagavi, Karnataka, INDIA.
}

\begin{abstract}
Introduction: Thiazolidinedione's are widely used synthetic antidiabetic agents. These agents affect the pumping power of heart muscle due to the formation of edema; limiting their usage in patients with congestive heart failure. The current study was aimed to perform in silico docking study of bioactive phytoconstituents from Cissus quadrangularis Linn. against the target Peroxisome proliferator-activated gamma (PPAR- $\gamma$ ). Materials and Methods: The docking study was performed by using AutoDock 4.2. The chemical constituents were retrieved from the PubChem database. The pharmacokinetic and toxicological parameters of each compound were predicted using PreADMET online server. The drug-likeness character of each compounds were predicted using Molsoft. Results: Quercetin scored highest drug-likeness character. Among the seven compounds, four compounds scored positive drug-likeness score. Qaudrangularin A showed highest binding affinity with the target protein. Discussion: All the compounds showed the binding affinity with the target protein suggesting that the compounds from Cissus quadrangularis can be utilized to target PPAR- $\gamma$ in the management of diabetes. The study suggests supporting the current study by performing wet lab experiments.
\end{abstract}

Key words: Cissus quadrangularis, Diabetes Mellitus, Lipinski rule of five, Molecular Docking, PPAR- $\gamma$.

\section{INTRODUCTION}

Diabetes mellitus is a metabolic disorder characterized by insulin resistance, defects in insulin secretion and high hepatic gluconeogenesis. ${ }^{1}$ Peroxisome Proliferator Activated Receptor-gamma (PPAR- $\gamma$ ) regulates lipid and glucose metabolism. ${ }^{2-5}$ Thiazolidinedione compounds have a high affinity for the PPAR $-\gamma$ receptors and used in the treatment of Diabetes Mellitus (DM). PPAR- $\gamma$ agonist opposes the effect of TNF- $\alpha$, improve the insulin resistance ${ }^{6}$ and adiponectin level and insulin sensitivity ${ }^{7,8}$ They also enhance the expression of a number of genes encoding proteins involved in glucose and lipid metabolism. ${ }^{9}$ However the thiazolidinedione pharmacotherapy is associated with various side effects ${ }^{4,10}$ leading to the search of new molecules.

Cissus quadrangularis $\mathrm{L}$. belongs to the family Vitaceae. That contains polyphenols, flavonoids and stilbenes as active biomol- ecules. ${ }^{11-13}$ Among them, Quadrangularin A, Kaempferol, Piceatannol, Resveratrol, Quercetin, Luteolin and Asarone are used in various medicinal purposes i.e. metabolic syndrome, weight loss, jaw fracture injuries and neuropharmacological effects. ${ }^{13-17}$

According to a review of the literature, there is no evidence to show the binding affinity of biomolecules from Cissus quadrangularis with PPAR- $\gamma$. Hence current study includes in silico docking analysis of active biomolecules from Cissus quadrangularis against the PPAR- $\gamma$.

\section{MATERIALS AND METHODS}

\section{Ligand Preparation}

All wo-dimensional (2D) and three dimensional (3D) structures of seven ligands were retrieved from PubChem chemical database. Canonical SMILES of each ligand
Submission Date: 18-09-2018; Revision Date: 28-12-2018; Accepted Date: 18-03-2019

DOI: 10.5530/ijper.53.3s.103 Correspondence: Mr. Pukar Khanal, Department of Pharmacology, KLE College of Pharmacy, KAHER, Belagavi- 590010 , Karnataka, INDIA. Phone: +917026072065 E-mail: pukarkhanal58@ gmail.com

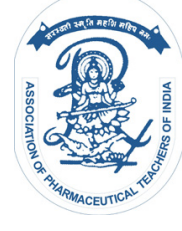

www.ijper.org 
were also collected. Each ligand was viewed in Discovery studio 2017 and saved into the PDB format. All the ligand molecules were minimized using Marvin sketch mmff9 4 force field. 2D images of all the selected ligand are shown in Figure 1.

\section{Protein Preparation}

Three-dimensional crystallographic structure of peroxisome proliferators-activated receptor- $\gamma$ (PDB ID: 4Y29) was retrieved from Protein Data Bank (www.rcsb.org). Discovery Studio 2017 was used to remove the water molecules and heteroatoms. A pocket of protein was analyzed using castP, Procheck and quality of protein were assessed using Errat online server. The first Pocket of protein molecule was chosen to dock the ligand against the protein. The protein was viewed in Ramachandran plot to understand the phi and psi scatter of amino acid residues shown in Figure 2.

\section{Pharmacokinetic (ADME) and Toxicological Predictions}

ADME and toxicological parameters of bioactive molecules were predicted by online PreADMET server (http://preadmet.bmdrc.org). This PreADMET server calculates pharmacokinetic and toxicological parameters based on the structure of the compound as BBB $\left(\mathrm{C}_{\text {brain }} /\right.$ $\mathrm{C}_{\text {blood }}$, human intestinal absorption (\%) plasma protein binding (\%), mutagenic and carcinogenic effects.

\section{Drug likeness Score of Bioactive Phytoconstituents}

Drug likeness of each compound was predicted via an online server, Molsoft (http://molsoft.com/mprop/) which is based on molecular weight, total number of hydrogen bond donors, the total number of hydrogen bond acceptors and $\log \mathrm{P}$.

\section{Ligand-Protein Docking}

The molecular docking was performed using AutoDock 4.2. The protein was added with hydrogen atoms and Kollman charges. The grid box was set and docking was carried using Lamarckian Algorithm. After docking the dlg file was used to identify the best pose of ligand based on the binding energy. Finally, the pose having lowest binding energy was selected to visualize the ligand-protein interaction.

\section{RESULTS AND DISCUSSION}

The current study was carried out to understand the drug-likeness character of phytoconstituents from Cissus quadrangularis and their binding affinity with PPAR$\gamma$. The Lipinski Rule of five states that compounds have poor absorptivity and bioavailability if their molecular weight is $>500 \mathrm{~g} / \mathrm{mol},>5$ hydrogen bond donors, $>5$ $\log P$ and $>10$ hydrogen bond acceptors. ${ }^{18}$ Among the selected compounds, Quercetin scored highest druglikeness score i.e. 0.93 and Quadrangularin A scored lowest i.e. 0.48. However, Quadrangularin A violated two rules of Lipinski of five based on its $\log \mathrm{P}$ and number of hydrogen bond donor. Compounds Piceatannol, Resveratrol and Asarone scored non-drug-likeness character of $-0.43,-0.94$ and -1.72 respectively. Although they scored non-drug likeness character, they did not violate any Rule of five (Table 1).

The ADMET parameters were predicted by PreADMET online server. All the seven compounds showed 60 to $100 \%$ of human intestinal absorption, 89 to 100\% plasma protein binding, CYP2C19, CYP2C9 and CYP3A4 inhibition. All seven compounds were a mutagen and have a medium risk on hERG inhibition. Quadrangularin A and Asarone showed carcinogenicity in mice, whereas Quadrangularin A, Kaempferol, Quercetin, Luteolin and Asarone showed carcinogenicity in

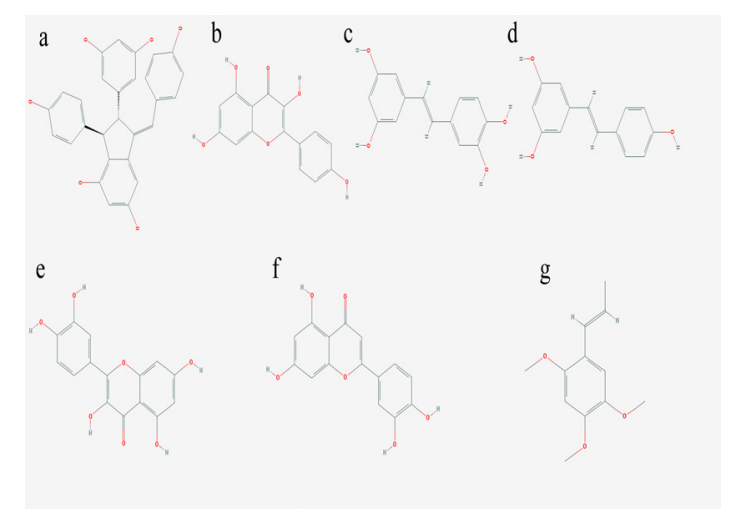

Figure 1: 2D Chemical Structures of a) Quadrangularin A, b) Kampferol, c) Piceatannol, d) Resveratrol, e) Quarcetin, f) Luteolin and g) Asarone.
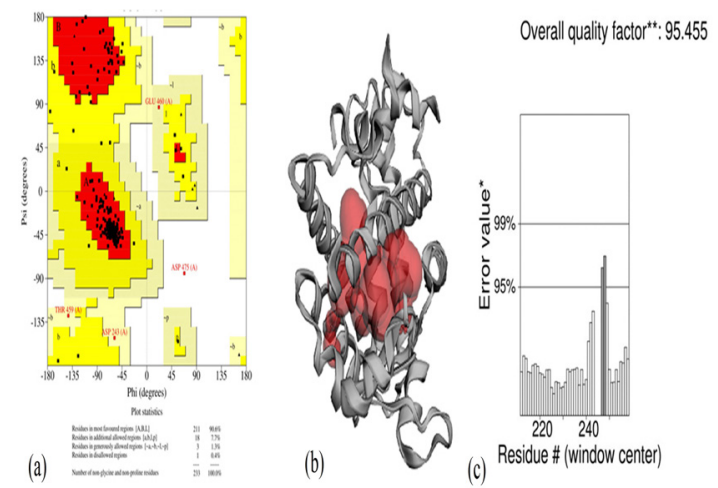

Figure 2: a) Ramachandran Plot of Protein Molecules b) 3D Structure of PPAR-y protein molecule with its pocket c) Quality of the protein molecule. 
the rat. The pharmacokinetic and toxicological parameters of all seven compounds are shown in Table 2.

In docking studies, Binding Energy (BE) of each bioactive molecule with the protein molecule was calculated by, $\mathrm{BE}=\mathrm{A}+\mathrm{B}+\mathrm{C}-\mathrm{D}$ where, $\mathrm{A}$ denotes desolva- tion energy + final intermolecular energy + hydrogen bonds + van der Walls energy + electrostatic energy, B denotes final total internal energy, $\mathrm{C}$ denotes torsional free energy and D denotes unbound system's energy.

\begin{tabular}{|c|c|c|c|c|c|}
\hline Compounds & Molecular weight $(\mathrm{g} / \mathrm{mol})$ & $\log P$ & $\begin{array}{c}\text { No. of hydrogen bond } \\
\text { donor }\end{array}$ & $\begin{array}{l}\text { No. of hydrogen } \\
\text { bond acceptor }\end{array}$ & Druglikness score \\
\hline Acceptable Values & $<500$ & $<5$ & $<5$ & $<10$ & 0.48 \\
\hline Kampferol & 286.05 & 2.49 & 4 & 6 & 0.77 \\
\hline Piceatannol & 244.07 & 3.27 & 4 & 4 & -0.43 \\
\hline Resveratrol & 228.08 & 3.65 & 3 & 3 & -0.94 \\
\hline Quarcetin & 302.04 & 2.11 & 5 & 7 & 0.93 \\
\hline Luteolin & 286.05 & 2.68 & 4 & 6 & 0.86 \\
\hline Asarone & 208.11 & 3.23 & 0 & 3 & -1.72 \\
\hline
\end{tabular}

Log P: Octanol/water partition coefficient.

\begin{tabular}{|c|c|c|c|c|c|c|c|}
\hline \multirow{2}{*}{ ADME } & \multicolumn{7}{|c|}{ Compounds } \\
\hline & $\underset{\text { A }}{\text { Quadrangularin }}$ & Kampferol & Piceatannol & Resveratrol & Quercetin & Luteolin & Asarone \\
\hline BBB $(\log B B)$ & $\begin{array}{c}2.12 \\
30\end{array}$ & 0.2860 & 1.0139 & 1.7381 & 0.1727 & 0.3675 & 1.2299 \\
\hline $\mathrm{CaCO}_{2} \mathrm{p}(\mathrm{nm} / \mathrm{sec})$ & 19.4829 & 9.5774 & 2.3774 & 5.1917 & 3.4129 & 4.5397 & 58.0986 \\
\hline BS (mg/L) & 0.0588 & 22.0776 & 100.621 & 33.995 & 64.479 & 220.694 & 263.651 \\
\hline CYP2C19 & 1 & I & I & I & 1 & I & I \\
\hline CYP2C9 & 1 & 1 & 1 & 1 & 1 & 1 & 1 \\
\hline CYP2D6 & $\mathrm{NI}$ & $\mathrm{NI}$ & $\mathrm{NI}$ & $\mathrm{NI}$ & $\mathrm{NI}$ & $\mathrm{NI}$ & $\mathrm{NI}$ \\
\hline CYP3A4 & 1 & 1 & 1 & 1 & 1 & 1 & I \\
\hline $\mathrm{HIA}(\%)$ & 86.6317 & 79.4392 & 81.9615 & 88.4794 & 63.4852 & 79.4272 & 100.00 \\
\hline P-gp & 1 & $\mathrm{NI}$ & $\mathrm{NI}$ & $\mathrm{NI}$ & $\mathrm{NI}$ & $\mathrm{NI}$ & $\mathrm{NI}$ \\
\hline $\mathrm{SP}(\log K p, \mathrm{~cm} / \mathrm{h})$ & -2.80 & -4.32 & -3.40 & -3.15 & -4.43 & -4.28 & -1.68 \\
\hline PPB (\%) & 100.00 & 89.60 & 100.00 & 100.00 & 93.23 & 99.71 & 93.39 \\
\hline Water solubility (mg/L) & 14.15 & 127.30 & 260.26 & 338.98 & 96.43 & 121.50 & 126.66 \\
\hline \multicolumn{8}{|c|}{ Toxicity parameters } \\
\hline Ames Test & M & M & M & M & M & M & $M$ \\
\hline Carcinogenicity (Mouse) & + ve & $-v e$ & - ve & - ve & - ve & - ve & + ve \\
\hline Carcinogenicity (Rat) & + ve & + ve & - ve & - ve & + ve & + ve & + ve \\
\hline hERG Inhibition & MR & MR & MR & MR & MR & MR & MR \\
\hline FAT (Medika) & 0.000161 & 0.064253 & 0.018625 & 0.016774 & 0.077880 & 0.032988 & 0.066864 \\
\hline FAT (Minnow) & 0.000120 & 0.029488 & 0.011938 & 0.011265 & 0.033502 & 0.016905 & 0.061897 \\
\hline
\end{tabular}

BBB: Blood-Brain Barrier, $\mathrm{CaCO}_{2}$ p: the Predicted value of intestinal absorption through $\mathrm{CaCO}_{2} \mathrm{p}: \mathrm{CaCO}_{2}$ permeability, BS: Buffer Solubility, hERG Inhibition: the Predicted result of hERG inhibition by compounds. hERG inhibition leading to QT prolongation and further cardiac risk, P-gp: P-glycoprotein, PPB: Plasma Protein Binding, HIA: Human Intestinal Permeability, SP: Skin Permeability, FAT: Fish Aqueous Toxicity, I=Inhibitor, I=Non Inhibitor=Mutagen, MR=Medium Risk. 
Among the selected compounds, Quadrangularin A showed the highest binding affinity with PPAR- $\gamma$ whereas Asarone showed the least (Table 3). On looking to the hydrogen bond interaction, Kaempferol scored the highest number of hydrogen bond interaction towards PPAR- $\gamma$ receptor via six bonds. Amino acid residues of the protein that interact with Kaempferol are GLN A: 410, SER A: 394, ARG A: 443, GLU A: 324, GLN A: 437 and THR A: 440. Asarone scored lowest hydrogen bond interaction to the protein molecule via one hydrogen bond interaction i.e. ARG A: 443. The amino acid residues of PPAR- $\gamma$ i.e. GLU A: 324, ASP A: 396, SER A: 394 interact with Quadrangularin A via three bonds. GLN A:437, GLU A:324 are the amino acid residues of the protein that interact with Piceatannol. Similarly SER A: 394, GLU A: 324, ARG A:443 are the amino acid residues of protein molecule that interact with Resveratrol. GLU A: 324, MET A:439 are the amino acid residues of the protein that interact with Quercetin. Luteolin interacts with two amino acid resi- dues of protein molecule i.e. GLU A:324, SER A:394 via two bonds.

On comparing all seven compounds, Luteolin can be choice of compound to bind with the PPAR $-\gamma$ receptor. This is because Quadrangularin A fails to obey the Rule of Five and Quercetin has a less binding affinity with PPAR $-\gamma$ compared to Luteolin. Although the docking study of Piceatannol, Resveratrol and Asarone showed binding affinity with PPAR $-\gamma$, the compounds were rejected by Lipinski rule of five. Hence, these phytochemicals may not be considered as drug molecules. The binding energy of individual compounds with PPAR- $\gamma$ is shown in Table 3. The ligand parameters of individual molecules are shown in Table 4. The interaction of each ligand with PPAR- $\gamma$ is shown in Figure 3.

PPAR- $\gamma$ agonist promotes adipogenesis and accelerates adipocytes differentiation by promoting the uptake of Free Fatty Acid (FFA) in subcutaneous adipose tissues. An agonist of PPAR- $\gamma$ decreases circulating FFA and thereby decreases associated insulin resistance. ${ }^{7}$ Com-

\begin{tabular}{|c|c|c|c|c|c|c|c|c|c|c|}
\hline \multicolumn{2}{|c|}{ Table 3: Binding Energies of the Compounds Based on their Rank with PPAR-Y Receptor. } \\
\hline \multirow{2}{*}{ Compounds } & \multicolumn{7}{|c|}{ Binding energies of the compounds based on their rank (kcal/mol) } \\
\cline { 2 - 13 } & $\mathbf{1}$ & $\mathbf{2}$ & $\mathbf{3}$ & $\mathbf{4}$ & $\mathbf{5}$ & $\mathbf{6}$ & $\mathbf{7}$ & $\mathbf{8}$ & $\mathbf{9}$ & $\mathbf{1 0}$ \\
\hline Quadrangularin A & -5.75 & -5.36 & -5.23 & -4.87 & -4.85 & -4.66 & -4.56 & -4.54 & -4.47 & -4.1 \\
\hline Kampferol & -5.02 & -4.89 & -4.78 & -4.72 & -4.71 & -4.69 & -4.68 & -4.43 & -4.35 & -4.16 \\
\hline Piceatannol & -5.02 & -5.00 & -4.85 & -4.77 & -4.76 & -4.63 & -4.35 & -4.34 & -3.79 & -3.50 \\
\hline Resveratrol & -4.68 & -4.63 & -4.55 & -4.54 & -4.52 & -4.44 & -4.29 & -4.05 & -3.92 & -3.65 \\
\hline Quarcetin & -5.51 & -5.27 & -5.12 & -4.97 & -4.77 & -4.71 & -4.63 & -4.49 & -4.48 & -4.19 \\
\hline Luteolin & -5.68 & -5.54 & -5.33 & -5.24 & -5.24 & -5.23 & -5.12 & -4.85 & -4.82 & -4.67 \\
\hline Asarone & -4.29 & -4.29 & -4.13 & -4.11 & -4.06 & -4.04 & -4.03 & -3.94 & -3.92 & -3.82 \\
\hline
\end{tabular}

\begin{tabular}{|c|c|c|c|c|}
\hline \multicolumn{5}{|c|}{ Table 4: Ligand Parameters. } \\
\hline Compounds & $\begin{array}{c}\text { Molecular } \\
\text { formula }\end{array}$ & $\begin{array}{c}\text { Aromatic } \\
\text { carbons }\end{array}$ & $\begin{array}{c}\text { Rotatable } \\
\text { bonds }\end{array}$ & $\begin{array}{c}\text { Number } \\
\text { of Torsions }\end{array}$ \\
\hline Quadrangularin A & $\mathrm{C}_{28} \mathrm{H}_{22} \mathrm{O}_{6}$ & 27 & 9 & 9 \\
\hline Kampferol & $\mathrm{C}_{15} \mathrm{H}_{10} \mathrm{O}_{6}$ & 15 & 5 & 5 \\
\hline Piceatannol & $\mathrm{C}_{14} \mathrm{H}_{12} \mathrm{O}_{4}$ & 12 & 6 & 6 \\
\hline Resveratrol & $\mathrm{C}_{14} \mathrm{H}_{12} \mathrm{O}_{3}$ & 12 & 5 & 5 \\
\hline Quarcetin & $\mathrm{C}_{15} \mathrm{H}_{10} \mathrm{O}_{7}$ & 15 & 6 & 6 \\
\hline Luteolin & $\mathrm{C}_{15} \mathrm{H}_{10} \mathrm{O}_{6}$ & 15 & 5 & 5 \\
\hline Asarone & $\mathrm{C}_{12} \mathrm{H}_{16} \mathrm{O}_{3}$ & 6 & 4 & 4 \\
\hline
\end{tabular}




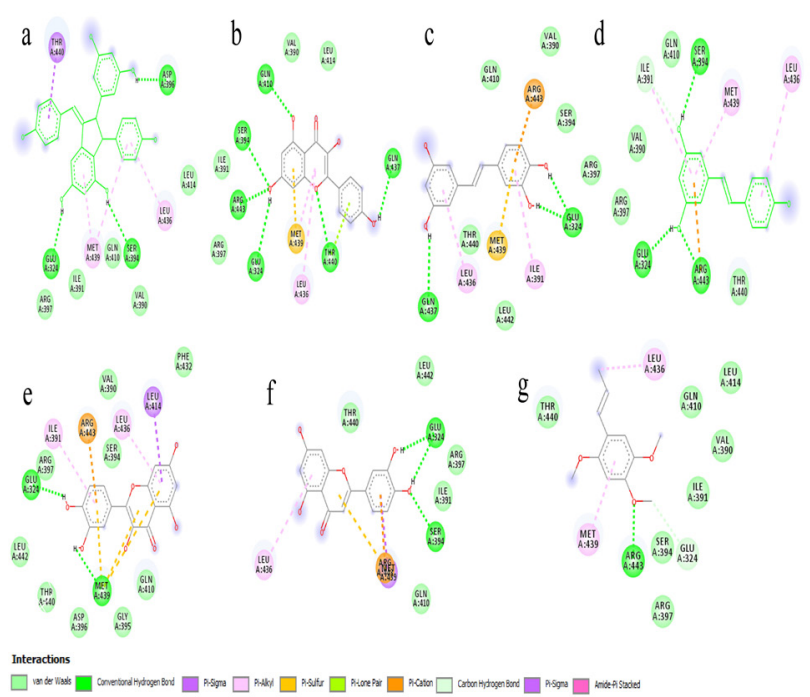

Figure 3: Interaction of a) Quadrangularin A, b) Kaempferol, c) Piceatannol, d) Resveratrol, e) Quercetin, f) Luteolin and g) Asarone with the PPAR-y receptor.

parison of docked phytochemical constituents has a different binding affinity, hydrogen bond interaction and drug-likeness property. These chemical constituents may play important role in the regulation of PPAR- $\gamma$ receptor and helpful in the treatment of diabetes mellitus.

\section{CONCLUSION}

The result obtained from the study confirms the hypothesis that seven chemical constituents of Cissus quadrangularis interact with the PPAR $-\gamma$ receptor, may bring about the physiological changes in the patient suffering from diabetes mellitus. The binding energies of the proteinligand interactions also confirm that the ligand fit into the active pockets. Further in vitro and in vivo study of these phytoconstituents may replace the thiazolidinedione molecules could help in the development of novel anti-diabetic molecules.

\section{ACKNOWLEDGEMENT}

The authors are thankful to Dr. B. M. Patil, Principal of KLE College of Pharmacy, Belagavi and Dr. N. A. Khatib, Head of Department of Pharmacology for the encouragement of work.

\section{CONFLICT OF INTEREST}

The authors declare no conflict of interest.

\section{ABBREVIATIONS}

ADMET: Absorption Distribution Metabolism Distribution Excretion Toxicity; BE: Binding energy; DM: Diabetes Mellitus; FFA: Free Fatty Acid; SMILES: Simplified Molecular-Input Line-Entry System; TNF: Tumour necrosis factor; DM: Diabetes Mellitus; FFA: Free Fatty Acid; SMILES: Simplified Molecular-Input Line-Entry System; TNF: Tumour necrosis factor.

\section{REFERENCES}

1. Jia Z, Sun Y, Yang G, Zhang A, Huang S, Heiney KM. New insights into the PPAR $y$ agonists for the treatment of diabetic nephropathy. PPAR Res. 2014;43:818530.

2. Grygiel-Górniak B, Mosor M, Marcinkowska J, Przysławski J, Nowak J. Impact of the PPAR gamma-2 gene polymorphisms on the metabolic state of postmenopausal women. J Bio Sci. 2016;41(3):427-37.

3. Pattanayak AK, Bankura B, Balmiki N, Das TK, Chowdhury S, Das M. Role of peroxisome proliferator-activated receptor gamma gene polymorphisms in type 2 diabetes mellitus patients of West Bengal, India. J Diabetes Investig. 2014;5(2):188-91.

4. Picard F, Auwerx J. PPAR-y and glucose homeostasis. Annu Rev Nutr. 2002;22(1):167-97.

5. Christodoulides C, Vidal-Puig A. PPARs and adipocyte function. Mol Cell Endocrinol. 2010;318(1-2):618.

6. Kim H, Ahn Y. Role of peroxisome proliferator-activated receptor-y in the glucose-sensing apparatus of liver and $\beta$-cells. Diabetes. 2004;53(Suppl 1):1-6.

7. Variya BC, Modi SJ, Savjani JK, Patel SS. In silico molecular docking and pharmacokinetic prediction of gallic acid derivatives as ppar-y agonists. Int J Pharm Pharm Sci. 2016;9(1):102.

8. Murphy GJ, Holder JC. PPAR-y agonists: Therapeutic role in diabetes, inflammation and cancer. Trends Pharmacol Sci. 2000;21(12):469-74.

9. Tyagi S, Sharma S, Gupta P, Saini A, Kaushal C. The peroxisome proliferatoractivated receptor: A family of nuclear receptors role in various diseases. J Adv Pharm Technol Res. 2011;2(4):236.

10. Yki-j H. Thiazolidinediones. N Engl J Med. 2004;351(11):1106-18.

11. Meenambiga SS, Rajagopal K. In silico studies on plant derived components of Cissus quadrangularis against COX-2 enzyme. Int J Pharm Pharm Sci. 2014;6(8):483-7.

12. Nagani K, Kevalia J, Chanda S. Pharmacognostical and Phytochemical evaluation of stem of Cissus quadrangularis L. IJPSR. 2011;2(11):2856-62.

13. Mukherjee T, Saha N, Palbag S. Ethnopharmacology, phytochemistry and pharmacology of ayurvedic plant hadjod - Cissus quadrangularis L. Int J Res Ayurveda Pharm. 2016;7(4):78-83.

14. Adesanya SA, Boukamcha N, Montagnac A, Pai M. Stilbene Derivatives from Cissus quadrangularis. J Nat Prod. 1999;62(12):1694-5.

15. Taylor P, Singh G, Rawat P, Maurya R. Formerly Natural Product Letters Constituents of Cissus quadrangularis. Natural Product Research. 2007;21(6)37-41.

16. Kaur R, Malik CP. Cissus quadrangularis L - Its Botany, Chemistry and Medicinal Importance : A Review. IJPCR. 2014;6(1):27-35.

17. Prabhavathi RM, Prasad MP, Jayaramu M. Studies on Qualitative and Quantitative Phytochemical Analysis of Cissus quadrangularis. Adv Appl Sci Res. 2016;7(4):11-7.

18. Roy N. Recent trends in drug-likeness prediction: A comprehensive review of in silico methods. Indian J Pharm Sci. 2017;69(5):609-15. 


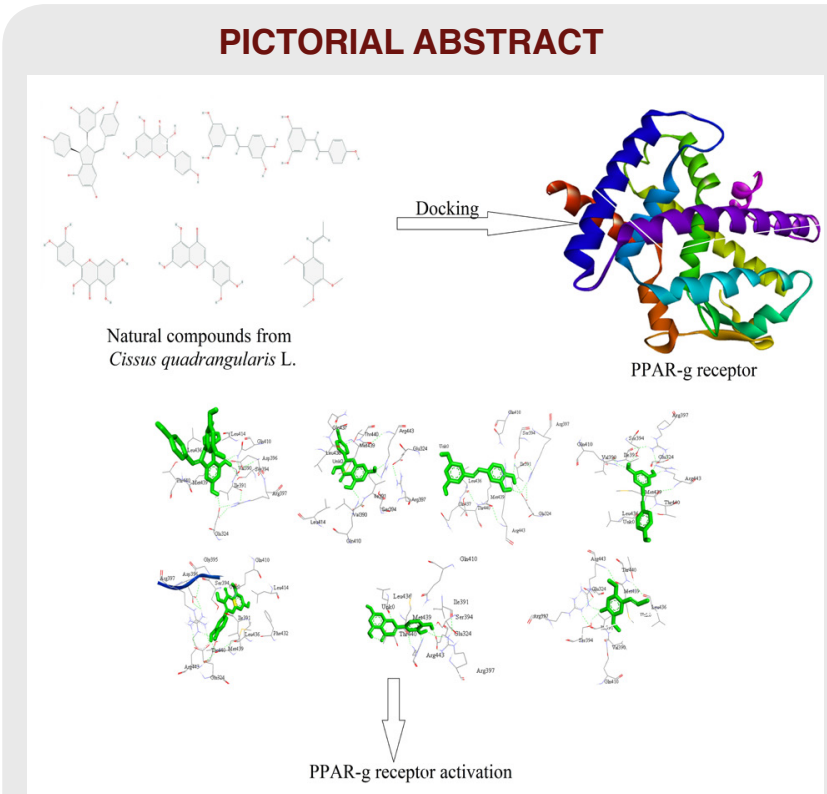

\section{SUMMARY}

In the current study, six active biomolecules were screened against the PPAR $-\gamma$ to assess the binding affinity, followed by the prediction of the ADMET. All the active biomolecules were predicted for the safety and efficacy under the various models to understand their pharmacokinetic and pharmacokinetic parameters. Toxicity of each compound was also predicted under various biological models. The outcome of the current study reflects to perform the wet lab experiments and the further confirmations are to be made via in vitro and in vivo studies.

\section{About Authors}

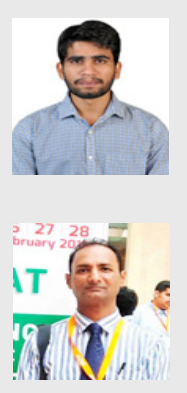

Vishal Shivalingappa Patil is currently M. Pharm second-year student, Department of Pharmacology at KLE College of Pharmacy, KAHER, Belagavi. His area of interest includes Neuropharmacology and Metabolic disorders. He is currently working on Neuropharmacological evaluation of herbal plants. Further, his area of interest is reverse Pharmacology.

Prakash Rajashekhar Biradar has eleven years of teaching experience and currently working as Asst. Professor, at Department of Pharmacology, KLE College of Pharmacy, KAHER, Belagavi. His area of interest includes Aphrodisiac activity and Metabolic Disorders.

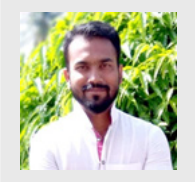

Vasim Attar is M. Pharm second year student, Department of Pharmacology at KLE College of Pharmacy, KAHER, Belagavi. His area of interest is the Evaluation of phytoconstituents for Metabolic Disorders. Further, he is interested in Aphrodisiac, Neuropharmacology and molecular dynamics.

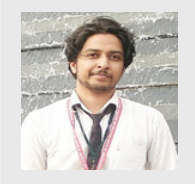

Pukar Khanal has been awarded with two times gold medal for his academic performance in B. Pharm and M. Pharm; currently working as Ph.D Research Scholar at KLE Academy of Higher Education and Research, Belagavi. His area of interest covers gene set enrichment analysis of lead molecule modulated pathway identification, protein-protein network interaction, in silico molecular docking, protein modeling and utilizing Danio rerio as a preliminary animal model. Further, he interests to utilize regression models for the evaluation of PKPD profiles and data correlation with wet lab protocols.

Cite this article: Patil VS, Biradar PR, Attar V, Khanal P. In silico Docking Analysis of Active Biomolecules from Cissus quadrangularis L. against PPAR- $\gamma$. Indian J of Pharmaceutical Education and Research. 2019;53(3 Suppl 2):s332-s337. 